This item was submitted to Loughborough's Research Repository by the author.

Items in Figshare are protected by copyright, with all rights reserved, unless otherwise indicated.

\title{
Tortuosity model to predict the combined effects of crystallinity and nano- sized clay mineral on the water vapour barrier properties of polylactic acid
}

\section{PLEASE CITE THE PUBLISHED VERSION}

http://dx.doi.org/10.1016/j.clay.2017.02.014

\section{PUBLISHER}

(C) Elsevier

VERSION

AM (Accepted Manuscript)

\section{PUBLISHER STATEMENT}

This work is made available according to the conditions of the Creative Commons Attribution-NonCommercialNoDerivatives 4.0 International (CC BY-NC-ND 4.0) licence. Full details of this licence are available at: https://creativecommons.org/licenses/by-nc-nd/4.0/

\section{LICENCE}

CC BY-NC-ND 4.0

\section{REPOSITORY RECORD}

Tan, Bowen, and Noreen L. Thomas. 2017. "Tortuosity Model to Predict the Combined Effects of Crystallinity and Nano-sized Clay Mineral on the Water Vapour Barrier Properties of Polylactic Acid". figshare. https://hdl.handle.net/2134/24839. 


\title{
Tortuosity model to predict the combined effects of crystallinity and nano-sized
} clay mineral on the water vapour barrier properties of polylactic acid

Bowen Tan and Noreen Louise Thomas*

\author{
Department of Materials, Loughborough University, Ashby Road, \\ Loughborough, Leicestershire, LE11 3TU, UK \\ *N.L.Thomas@lboro.ac.uk, Tel. +44(0)1509223334
}

\begin{abstract}
The combined effects of crystallinity and nano-sized clay mineral (montmorillonite) fillers on the water vapour barrier properties of poly(lactic acid) (PLA) nanocomposites are investigated. Both amorphous and semi-crystalline PLA nanocomposites containing 0 to $5 \mathrm{wt} \%$ montmorillonite clay are prepared by melt compounding followed by compression moulding with two different thermal treatments: quenching and annealing. Thermal properties and morphology are investigated using differential scanning calorimetry (DSC), polarised light microscopy, transmission electron microscopy (TEM) and wide-angle X-ray diffraction (WAXD). It is confirmed that the nanocomposite structures are intercalated and the montmorillonite aspect ratio is measured to be 40 in both quenched and annealed samples. Water vapour transmission rates (WVTR) through the film samples are measured. A new tortuous path model is developed that fits the WVTR data and accounts for the effects of crystallinity as well as montmorillonite aspect ratio, concentration and orientation.
\end{abstract}


Key words: poly(lactic acid), montmorillonite (Mt), crystallinity, water vapour permeability, tortuosity model, nanocomposites

\section{Introduction}

The development of bio-based and compostable polymers in recent years has been in response to growing concerns about the environmental impact of plastic waste. Poly(lactic acid) (PLA) is one of the most commercially successful bio-plastics. Its monomer, lactic acid, is derived from renewable sources, such as starch or maize sugar, through fermentation (Garlotta, 2002). Since lactic acid has an asymmetric carbon atom, it has two optically active configurations (L- and D-lactic acid). Commercial PLA is produce by ring-opening polymerization of the lactide (Lim et al., 2008), which is a dimer of lactic acid. The two configurations can form into three forms of lactide: L-lactide (a dimer of L-lactic acid); D-lactide (a dimer of D-lactic acid) and meso-lactide (a dimer of L- and D-lactic acid). The crystallisability of PLA is dependent on the ratio of L-, D- and meso-lactide in the polymer backbone: higher crystallinities are obtained with the more optically pure polymers because of their higher chain symmetry (Madhavan Nampoothiri et al., 2010). PLA resin that contains $50 \%-93 \%$ L-lactic acid is amorphous and PLA with L-lactic acid higher than $93 \%$ is semi-crystalline (Auras et al., 2004).

A challenge posed by compostable polymers is that they tend to have poor water barrier properties compared with conventional thermoplastics. This is because they are polar polymers and therefore have high water vapour solubility and hence high permeability. One way of addressing this problem is through the development of clay mineral polymer nanocomposites, which have been very successful in improving barrier properties (LeBaron et al., 1999; Neppalli et al., 2014; Tan and Thomas, 2016). 
At relatively low additions of nano-sized clay mineral, it is possible to achieve quite dramatic reductions in permeability to both gases and water vapour. For example, Yano et al. reported a reduction of $83 \%$ in water vapour permeability in a polyimide/montmorillonite nanocomposite with a montmorillonite loading of $8 \mathrm{wt} . \%$ (Yano et al., 1993). In a further study (Yano et al., 1997), a reduction of water vapour permeability of up to $90 \%$ was reported for a polyimide/mica composite with a mica content of only $2 \mathrm{wt} . \%$. These researchers demonstrated that the barrier properties of the nanocomposites are greatly affected by the length of the clay mineral filler particles.

It is generally accepted that the mechanism by which the barrier properties of polymer nanocomposites are improved is by a so-called 'tortuous path' effect. In this model, the diffusion path length of gas or water vapour molecules is dramatically increased due to obstacles created by impervious particles, as illustrated in Figure 1. The model was first proposed by Nielsen (Lawrence E. Nielsen, 1967), who quantified the permeability of polymer/filler composites. In the 'Nielsen model', the single layers of clay mineral are assumed to be circular or rectangular, evenly dispersed and aligned perpendicular to the diffusion direction. The Nielsen model is given in equation (1).

$\frac{P_{F}}{P_{u}}=\frac{\emptyset_{P}}{\tau}$

Where $P_{F}$ represents the permeability of the polymer composite, $P_{u}$ represents the permeability of the unfilled polymer, $\emptyset_{P}$ is the volume fraction of the polymer, $\tau$ is the tortuosity factor as defined below:

$$
\tau=\frac{\text { distance a molecule must travel to get through film }}{\text { thickness of film }}
$$


In the Nielsen model the tortuous path is assumed to be the maximum distance that a diffusing molecule must travel, therefore $\tau$ is expressed as:

$\tau=1+(\mathrm{L} / 2 \mathrm{D}) \emptyset_{\mathrm{P}}$

where, $L$ and $D$ are the average length and thickness of the filler platelets and $\emptyset_{F}$ is the volume fraction of the filler.

Combining equations (1) and (2), the permeability equation becomes:

$\frac{P_{F}}{P_{u}}=\frac{1-\emptyset_{F}}{1+(L / 2 D) \emptyset_{F}}$

Many models have been proposed to explain water vapour transport behaviour in polymer nanocomposites films. Tan and Thomas (Tan and Thomas, 2016) have reviewed the existing models for the prediction of moisture barrier properties of polymer nanocomposites and discussed anomalous phenomena that influence moisture barrier properties. Among these models, that due to Nielsen is the most commonly used to predict permeability and, despite its simplicity, the Nielsen equation has proved to be remarkably successful. For example, Yano et al (Yano et al., 1993) used the Nielsen equation to model the gas permeability of polyimide/montmorillonite nanocomposites. It was reported that the experimental results of gas permeability fitted the theoretical line predicted from the Nielsen model. In a recent study, Duan et al. (Duan et al., 2013) showed that water vapour transmission rates through films of poly(lactic acid)/montmorillonite nanocomposites fitted well with the Nielsen equation.

It is generally agreed that the barrier properties of polymer membranes are related to crystallinity because impervious crystallites can act as barriers to the diffusion path of 
gases and water vapour molecules (Drieskens et al., 2009). One of the earliest papers on this was by Michaels et al. (Michaels et al., 1963), who studied diffusion of various gases in glassy and rubbery polyethylene terephthalate in the temperature range 25 to $130^{\circ} \mathrm{C}$. They found that below the glass transition temperature $\left(T_{g}\right)$, diffusion was impeded by the presence of crystallites to an extent dependent on the reciprocal of the amorphous volume fraction. The effects of crystallisation polymorphism and crystallinity on the water vapour permeability of poly(L-lactic acid) has been studied by Cocca et al. (Cocca et al., 2011). They reported that water vapour permeability decreased slightly at low degrees of crystallinity but suddenly dropped dramatically when the crystallinity reached a certain range between 0.39 and 0.4. This rapid decrease in water vapour permeability was attributed to the change of crystal conformation from $\alpha^{\prime}$ to $\alpha$.

Duan and Thomas (Duan and Thomas, 2014) have modified the Nielsen equation to predict the water vapour permeability of semi-crystalline PLA films by assuming that the spherulites are impermeable spherical particles. Hence, in equation (3) if $L=D$ and the volume fraction $\left(\emptyset_{F}\right)$ is replaced by the degree of crystallinity $\left(X_{c}\right)$, then the Nielsen model becomes

$\frac{P_{\text {crystalline }}}{P_{\text {amorphous }}}=\frac{1-X_{C}}{1+\frac{1}{2} X_{C}}$

In their study, a series of semi-crystalline PLA samples with crystallinity ranging from 0 to $50 \%$ was tested and the experimental results of water vapour permeability were found to fit well with the modified Nielsen model in equation (4).

In terms of gas permeation, Picard et al. (Picard et al., 2011) predicted the effect of crystallinity on the oxygen barrier properties of semi-crystalline PLA nanocomposites 
using the Nielsen model (with $\mathrm{L}=\mathrm{D}$ ), and found good agreement between the theoretical and experimental permeability for semi-crystalline PLA films.

The effect of nano-sized clay mineral on the water vapour barrier properties of PLA nanocomposites has been reported in a number of studies (Gorrasi et al., 2004; Rhim et al., 2009; Sanchez-Garcia et al., 2008; Thellen et al., 2005; Zenkiewicz and Richert, 2008; Zenkiewicz et al., 2010; Duan et al., 2013; Espino-Pérez et al., 2013; Tenn et al., 2013). However, there is a limited number of studies on the combined effect of crystallinity and clay mineral on the barrier properties. Only Picard et al. (Picard et al., 2011) investigated the effect of nano-sized montmorillonite on the gas barrier properties of both amorphous and annealed PLA nanocomposites. A reduction of $60 \%$ in oxygen permeability in an annealed PLA nanocomposite sample was shown to result from the respective contribution of the montmorillonite and the crystalline phase. Johansson and Clegg (Johansson and Clegg, 2015) investigated oxygen permeability of both annealed and non-annealed nanocomposites of ethylene-modified poly(vinyl alcohol), with three different bentonites. It was found that the most effective bentonites for the reduction of oxygen permeability was Na-montmorillonite and that the combined effects of annealing and the nano-sized clay mineral caused a further reduction in the oxygen permeability.

The aim of this paper is to investigate the combined effects of crystallinity and montmorillonite concentration on the water barrier properties of PLA films and to quantitatively model the results. PLA nanocomposites containing 0 to $5 \mathrm{wt} . \%$ montmorillonite are prepared by melt compounding followed by compression moulding with two different thermal treatments (i.e. quenching and annealing) to obtain amorphous and semi-crystalline samples. The morphology, thermal properties, and water vapour transmission rates of these samples are investigated. The 
combined effects of crystallinity and montmorillonite concentration on the water vapour barrier properties of PLA are investigated and a new tortuous path equation is derived to model the results.

\section{Experimental}

\subsection{Materials}

Two grades of polylactide (PLA) polymer (Ingeo ${ }^{\text {TM }}$ 4060D and 4032D) were supplied by Natureworks LLC (Minnetonka, MN, USA). 4060D is an amorphous polymer with an average D-lactide content of $12 \mathrm{wt} . \%$ and a glass transition temperature $(\mathrm{Tg})$ of $55-60^{\circ} \mathrm{C}$, whereas $4032 \mathrm{D}$ is semi-crystalline with an average D-lactide content of 1.4 wt. $\%$ and a melting point in the range $155-170^{\circ} \mathrm{C}$. The weight average molar mass $\left(M_{w}\right)$ of the two polymers as determined by gel permeation chromatography (GPC) were found to be $89,000 \mathrm{~g} / \mathrm{mol}$ and $94,000 \mathrm{~g} / \mathrm{mol}$ respectively. The specific gravity is $1.24 \mathrm{~g} / \mathrm{cm}^{3}$.

The clay mineral used in this study was Cloisite 30B obtained from Southern Clay Products (Gonzales, TX, USA). It is a montmorillonite clay that has been organically modified with an alkyl quaternary ammonium salt. This has the effect of lowering the surface energy of the montmorillonite and thereby improving its compatibility with the polymer matrix. It has a specific gravity of $1.98 \mathrm{~g} / \mathrm{cm}^{3}$.

\subsection{Preparation and processing of the PLA nanocomposites}

Before processing, the PLA granules were dried at $60^{\circ} \mathrm{C}$ for $24 \mathrm{hr}$ in a vacuum oven to remove excess moisture. The PLA was then melt blended with 20 wt. \% of Cloisite ${ }^{\circledR}$ 30B to make a masterbatch. Melt blending was carried out in a counter-rotating mixer (Haake Rheomix OS) at $170^{\circ} \mathrm{C}$ for $10 \mathrm{~min}$ with a constant rotor speed of $60 \mathrm{rpm}$. The 
masterbatch was then diluted by adding dried PLA to form further compositions ranging from $1-5 \mathrm{wt} . \%$ montmorillonite, for a further $10 \mathrm{~min}$. The control PLA material (neat PLA 4032D) was processed in the same way, so that it had the same thermal history as the PLA nanocomposites.

PLA sheets for water vapour permeability measurements were prepared by compression moulding. The materials were hot pressed at $180^{\circ} \mathrm{C}$ for $5 \mathrm{~min}$ at 15 tons, creating a pressure on the sheet of $11.3 \mathrm{MPa}$. Two different cooling protocols were used on the melt pressed sheets to produce amorphous and semi-crystalline sheets. The different regimes adopted are described below:

- Quenching: PLA sheets were quenched between water cooled plates at 5 tons, creating a pressure on the sheet of $3.8 \mathrm{MPa}$, for $3 \mathrm{~min}$. This method was applied to PLA 4060D to produce amorphous PLA nanocomposite sheets.

- Annealing: the quenched sheets were annealed at $115^{\circ} \mathrm{C}$ for 15 minutes at 5 tons. They were then cooled following the quenching procedure. This method was used for PLA 4032D to produce semi-crystalline PLA nanocomposite sheets.

The average thickness of the sheets was about $0.6 \mathrm{~mm} .5$ individual sheets were produce for each montmorillonite concentration and crystallinity.

\subsection{Characterisation techniques}

\subsubsection{Differential scanning calorimetry (DSC)}

The thermal properties of the PLA nanocomposites were investigated using differential scanning calorimetry (DSC). Measurements were performed using a DSC Q200 (TA Instruments, USA) fitted with an auto-sampler and mechanical cooler. 
Samples of approximately $10-15 \mathrm{mg}$ were cut out and enclosed in aluminium pans. A reference pan was loaded with the sample pan into the cell, which was sealed in a nitrogen atmosphere at a gas purging rate of $50 \mathrm{ml} / \mathrm{min}$ during the test. The samples were heated from $20^{\circ} \mathrm{C}$ to $200^{\circ} \mathrm{C}$ at a heating rate of $10^{\circ} \mathrm{C} / \mathrm{min}$. Then data was analysed using the TA universal analysis software. All the values represent the average of 5 samples.

The amount of overall crystallinity was calculated from the following equation:

$$
\% \text { Crystallinity }=\left[\frac{\Delta H_{m}-\Delta H_{c}}{93.1 \times w}\right] \times 100 \%
$$

where, $\Delta H_{m}$ is the measured heat of fusion; $\Delta H_{c}$ is the enthalpy of cold crystallisation; $93.1(\mathrm{~J} / \mathrm{g})$ is the enthalpy of fusion for $100 \%$ crystalline PLA; and $w$ is the weight fraction of PLA in PLA nanocomposites.

\subsubsection{Transmission electron microscopy}

Samples for transmission electron microscopy (TEM) were prepared by first cutting the compression moulded sheets into a pencil-like point and then shaving off thin slices (approximately $100 \mathrm{~nm}$ thick) at room temperature using a Cambridge Instruments ultra-microtome fitted with a diamond edge blade. A reservoir of de-ionised water was used to contain the sliced off sample pieces, which were then scooped onto a copper mesh and left on an absorbent paper to dry before being observed. TEM observation was carried out in a JEOL, JEM-2000FX electron microscope operated at an accelerating voltage of $100 \mathrm{kV}$. The aspect ratios of the single layers of the montmorillonite were measured from the TEM images using Image $\mathrm{J}^{\circledR}$ photograph software. 


\subsubsection{Optical microscopy}

Optical microscopy was used to study the crystalline morphology of the PLA sheets. Samples were observed between crossed polars in a Leica ${ }^{\circledR}$ DM LM binocular transmitted light microscope. The spherulite structure was observed at room temperature and then the samples were heated to $200^{\circ} \mathrm{C}$ using a hot stage facility at a rate of $10^{\circ} \mathrm{C} / \mathrm{min}$. This allowed observation of the cold crystallisation and melting behaviours.

\subsubsection{X-ray diffraction}

PLA nanocomposite samples were examined by wide-angle X-ray diffraction (WAXD) in order to investigate the extent of intercalation or exfoliation of the montmorillonite. The data were collected on a Brucker D8 Diffractometer using graphite-filtered Cu-Ka radiation $(\lambda=1.542 \mathrm{~nm})$. The diffractometer was controlled using Diffrac Plus XRD Commander and the raw data was manipulated using EVA software. The Mt/PLA nanocomposite sheets were laid flat on a plastic block. Each sample was carefully adjusted so that its surface was at the same level as the reference plane of the instrument. Each sheet was scanned over the angular region $(2 \theta)$ of $1-10^{\circ}$.

\subsubsection{Water vapour permeability measurements}

Water vapour transmission rates through the PLA nanocomposite sheets were measured using a MOCON (Modern Controls Inc., USA) Permatran-W@398 operated at $38^{\circ} \mathrm{C}$ and a relative humidity of $90 \%$. The data was calibrated using a 'Certified Yellow Film' standard with a WVTR of $23.53 \mathrm{gm} / \mathrm{m}^{2} /$ day at $37.8^{\circ} \mathrm{C}$. Three to five individual samples were measured for each formulation. 


\section{Results and discussion}

\subsection{Differential scanning calorimetry (DSC)}

The DSC first heating scan for amorphous PLA, grade 4060D, and PLA nanocomposites are shown in Figure 2 . The step change at $56^{\circ} \mathrm{C}$ relates to the glass transition temperature $\left(T_{g}\right)$ of the polymer. An endothermic peak is observed just after the glass transition temperature. This is associated with relaxation of non-equilibrium structure. It was observed that as the montmorillonite concentration increased the endothermic peak tended to disappear, which suggested that the addition of montmorillonite had a confining effect on polymer chain relaxation. However, the glass transition temperature (see Table 1) decreased slightly as the montmorillonite content increased in the PLA nanocomposites. This phenomenon may be due to a plasticising effect of the montmorillonite surfactant. A decrease in $T_{g}$ for PLA nanocomposites also has been reported in some previous studies (Fukushima et al., 2009; Pluta, 2006; Tenn et al., 2013). However, the opposite result was reported by Araújo et al. (Araújo et al., 2014), who found that the $T_{g}$ value of the Cloisite 30B/PLA nanocomposite increased from $48 .{ }^{\circ} \mathrm{C}$ to $57.3^{\circ} \mathrm{C}$ in a nanocomposite with $3 \mathrm{wt} \%$ montmorillonite loading. The increase in $T_{g}$ value was thought to be due to restricted segmental motion at the organic-inorganic interface of the intercalated compositions.

Since the PLA grade 4060D is amorphous, the DSC curves in Figure 2 do not show any cold crystallisation or melting peaks.

Figure 3 is the DSC first heating scan for the crystallisable PLA, grade 4032D, that had been annealed. The glass transition temperature is at $57^{\circ} \mathrm{C}$ and the melting point is at $170^{\circ} \mathrm{C}$. There is a small peak at about $162^{\circ} \mathrm{C}$ merging into the main melting peak. The occurrence of such a double melting peak in PLA has been previously 
reported (Ling and Spruiell, 2006; Pan et al., 2008, 2007; Picard et al., 2011; Sawai et al., 2002; Yasuniwa et al., 2004). One explanation of double melting is associated with melt-recrystallisation, which suggests that the high-temperature endotherm can be attributed to the melting of original crystals and the low-temperature endotherms are due to crystals formed through recrystallisation due to cold crystallisation. Sometimes double melting peaks can be associated with different crystalline forms. For example, Sawai et al. (Sawai et al., 2002) obtained both $\alpha$ crystal and $\beta$ crystals in uniaxially orientated PLLA and found double melting peaks in the DSC scan. The main melting peak corresponded to the melting of $\alpha$ crystals, whereas the lower temperature peak, at about $10^{\circ} \mathrm{C}$ below the main peak, was due to the melting of orientated $\beta$ crystal phases. In other cases the double peak is due to disordered crystallites. Pan et al. (Pan et al., 2008, 2007) observed double melting in PLLA and attributed it to the formation of a disordered $\alpha^{\prime}$ crystal phase. They proposed that the high temperature melting peak corresponded to melting of the $\alpha$ phase, which is the ordered crystalline form, whereas the lower peak corresponded to melting of the disordered $\alpha$, phase.

Annealed PLA nanocomposites were found to have different DSC heating scans from the annealed PLA as shown in Figure 4, which is the DSC heating scan for the annealed PLA nanocomposite with 5 wt.\% montmorillonite. Although, the glass transition temperature and the melting point are still at $57^{\circ} \mathrm{C}$ and $170^{\circ} \mathrm{C}$, the lower melting peak has virtually disappeared, showing that the montmorillonite has promoted formation of the more stable $\alpha$ crystal phase during annealing.

Table 1 Summarises the DSC result of samples with various montmorillonite concentrations. The crystallinity of annealed PLA nanocomposites was about $30 \%$, 
and montmorillonite concentration had no effect on the crystallinity of the annealed samples.

\subsection{Optical microscopy}

The crystalline morphology of a semi-crystalline PLA film produced by annealing at $115^{\circ} \mathrm{C}$ for 15 min was investigated in a hot stage optical microscope between crossed polars. A series of micrographs taken at different temperatures in the hot stage microscope when heated at a rate of $10^{\circ} \mathrm{C}$ per minute is shown Figure 5.

The change in the crystallite morphology can be interpreted in relation to the DSC scan in Figure 3. Some coarser spherulites in a background of tiny crystallites are observed at $115^{\circ} \mathrm{C}$ during the heating process. As the temperature reaches $160^{\circ} \mathrm{C}$, some small crystallites begin to blur, whereas the larger crystallites grow. When the temperature reaches the melting point, at $168^{\circ} \mathrm{C}$, the small crystallites blur into the dark background, whereas the large crystallites still exist. At $170^{\circ} \mathrm{C}$ the image becomes completely dark, indicating that all the crystallites have melted.

\subsection{X-ray diffraction}

The wide-angle X-ray traces (WAXD) traces for montmorillonite (Cloisite 30B) organoclay, PLA and PLA nanocomposite containing 3 wt.\% montmorillonite are shown in Figure 6 . In the trace of the montmorillonite, the reflection at $4.8^{\circ}$ corresponds to a clay interlayer spacing $\left(d_{001}\right)$ of $1.8 \mathrm{~nm}$. This value shifts to $2.7^{\circ}$ corresponding to an interlayer spacing of $3.3 \mathrm{~nm}$ in the PLA nanocomposite. This result indicates that the clay particles has become delaminated and widened within the PLA matrix, which means that an intercalated structure has been produced. 
The XRD result is in agreement with some other published WAXD data for PLA nanocomposites. For example, McLauchlin and Thomas (McLauchlin and Thomas, 2012) have reported that Cloisite $30 \mathrm{~B}$ has an interplanar spacing of $1.8 \mathrm{~nm}$, which increased to $3.5 \mathrm{~nm}$ in the intercalated PLA nanocomposites produced by solvent casting. Rhim et al. (Rhim et al., 2009) found that the interlayer distance of Cloisite $30 \mathrm{~B}$ was $1.86 \mathrm{~nm}$, while that for Cloisite $30 \mathrm{~B} / \mathrm{PLA}$ nanocomposite was increased to $3.14 \mathrm{~nm}$. Duan et al. (Duan et al., 2013) reported that the interlayer spacing of Cloisite 30B was increased from $1.84 \mathrm{~nm}$ to $3.4 \mathrm{~nm}$ after melt compounding with PLA.

The WAXD traces of quenched and annealed PLA nanocomposites with 3 wt.\% montmorillonite are compared, as shown in Figure 7 . It is found that the reflection associated with clay interlayer structure is still at $2.7^{\circ}$ after annealing, which means the interlayer spacing of montmorillonite did not change during annealing.

\subsection{Transmission electron microscopy}

The transmission electron micrographs of the quenched and annealed PLA nanocomposites containing $1 \mathrm{wt} . \%$ montmorillonite at low and high magnifications are shown in Figure 8. For the quenched samples, good alignment of the single layers is seen in the low magnification images. The alignment of the clay particles took place during melt compounding, and remains in the same direction as the polymer melt flow after cooling. The high magnification image shows intercalated structures of the nano-sized montmorillonite. The single layered silicates are delaminated in the PLA matrix.

However, for the annealed samples, the montmorillonite layers are randomly aligned in the low magnification image and well dispersed single layers can be observed in the high magnification image. Compared with the XRD result in Figure 7, it is 
concluded that the crystallisation process did not affect the dispersion state of the montmorillonite but has affected the alignment of the montmorillonite particles.

A micrograph of a $1 \mathrm{wt} . \%$ montmorillonite sample at $400 \mathrm{k}$ magnification is shown in Figure 9, in which the intercalated clay structure can be clearly observed. In these micrographs, the dark lines are the edges of the single layered silicate.

The length and thickness of the montmorillonite layers are able to be measured from the TEM micrographs using Image $\mathrm{J}^{\circledR}$ software. More than 200 montmorillonite platelets were measured from 7 high magnification micrographs with different montmorillonite content. The average length and thickness of the montmorillonite platelets was found to be $90 \pm 15 \mathrm{~nm}$ and $2.1 \pm 0.5 \mathrm{~nm}$, respectively. Hence, the average aspect ratio (length/thickness) of the organoclay within the PLA matrix was approximately 40. The transmission electron micrographs of annealed PLA nanocomposites containing 1 wt.\% at 200k magnifications are shown in Figure 10, from which the length and thickness of montmorillonite platelets after annealing can be measured. The average length and thickness of the montmorillonite platelets in the annealed nanocomposite was found to be $155 \pm 35 \mathrm{~nm}$ and $3.8 \pm 1.6 \mathrm{~nm}$, therefore, the aspect ratio of the montmorillonite was about 41 , which is similar to the value measure on the quenched nanocomposite samples.

\subsection{Water vapour permeability measurement}

\subsubsection{Interpretation by tortuous path models}

Water vapour transmission rate (WVTR) data for quenched and annealed PLA nanocomposite sheets was measured through the PLA sheets processed from the amorphous PLA, 4060D, and the crystallisable PLA, 4032D, respectively. The 
experimental data are shown in Table 2. The measured water vapour permeability data for the annealed samples is much lower than that of the quenched samples due to the crystallinity of the annealed PLA nanocomposites.

The data for the quenched PLA and PLA nanocomposites are plotted Figure 11. There is a significant decrease in water vapour permeability with increasing montmorillonite content, which levels off at $5 \mathrm{wt} . \%$ loading. The sample with $5 \mathrm{wt} \%$ montmorillonite shows the lowest permeability, which was reduced by about $37 \%$ compared with the neat PLA.

Since the quenched samples are amorphous, the reduction in water vapour permeability originates from the incorporation of nano-sized montmorillonite. The Nielsen model (equation (3)) was used to calculate the theoretical permeability of the PLA nanocomposites given that the aspect ratio (L/D) is 40 . A plot of permeability predicted from the Nielsen model is shown in Figure 11 compared with the experimental data. It is found that the line predicted from the Nielsen model is just below the experimental data points, indicating that the experimental data fit well. This is in agreement with the work of Duan et al. (Duan et al., 2013), who first fitted the permeability of PLA nanocomposites with the Nielsen model.

WVTR data for the annealed PLA and PLA nanocomposite samples as a function of weight $\%$ montmorillonite are plotted in Figure 12. A theoretical line predicted from the Nielsen model is plotted on the same graph. All the experimental data are found to be higher than the theoretical line and the reduction of permeability does not fit the Nielsen model. This is thought to be due to the effect of annealing on increasing crystallinity but also changing the alignment of the montmorillonite particles. 
According to the TEM images in Figure 8, the montmorillonite layers became more randomly aligned after annealing. Therefore, a model, due to Bharadwaj (Bharadwaj, 2001), that takes into account the orientation of the particles, was applied to the annealed data. Unlike the Nielsen model, which assumes the filler particles are aligned at right angles to the diffusion direction, this model allows for the filler particles to be oriented in different directions. In this model there is an orientation factor, $\mathrm{S}$, included in the tortuosity factor. The orientation factor is shown in equation (5), where $\theta$ is the angle between the perfect diffusion direction and the normal to the filler particles.

$S=\frac{1}{2}\left\langle 3 \cos ^{2} \theta-1\right\rangle$

In equation (5), when the filler particles are orientated perpendicular to the direction of diffusion (i.e. $\theta=0$ ) then $S=1$ and the equation becomes the same as the Nielsen model. However, if the filler particles are orientated parallel to the direction of diffusion (i.e. $\theta=\pi / 2$ ) then $S=-1 / 2$. When there is random orientation, then $S=0$.

The order parameter is inserted into the Nielsen equation to allow for orientation (Bharadwaj, 2001), as shown in equation (6)

$\frac{P_{F}}{P_{u}}=\frac{1-\emptyset_{F}}{1+\frac{L . \emptyset_{F}}{2 D}\left(\frac{2}{3}\right)\left(S+\frac{1}{2}\right)}$

This model is fitted to the WVTR data from the annealed samples in Figure 13. The best fit between the experimental data and the predicted line was found with a regression coefficient, $R^{2}$, of 0.8 when $S=0.15$, which indicates that the orientation of the montmorillonite particles was in a nearly random state. 


\subsubsection{Building a new model and interpretation}

In the Nielsen model, the tortuosity factor is the maximum possible value given by

$$
\tau=1+(\mathrm{L} / 2 \mathrm{D}) \emptyset_{\mathrm{F}}
$$

In the case of a crystalline polymer without filler, the spherical crystals are assumed to be impermeable fillers with $L=D$. Exchanging the volume fraction of fillers for the fractional degree of crystallinity, $X_{c}$, the tortuosity factor is given by

$\tau=1+\frac{1}{2} X_{C}$

Then the Nielsen equation is modified to give equation (4), in which $\mathrm{P}_{c}$ is the permeability of the semi-crystalline polymer, $\mathrm{P}_{0}$ is the permeability of the amorphous polymer, and $X_{c}$ is the fractional degree of crystallinity (Duan and Thomas, 2014).

$\frac{P_{C}}{P_{0}}=\frac{1-X_{c}}{1+\frac{1}{2} X_{c}}$

In the present study, the permeability of the annealed PLA $\left(\mathrm{P}_{\mathrm{C}+0 \% \mathrm{Mt}}\right)$ can be predicted by using equation (4) with a known crystallinity of $\mathrm{X}_{\mathrm{c}}=0.3$ (Table 1) and $\mathrm{P}_{0}=$ $180 \mathrm{~g}-\mathrm{mil} /\left[\mathrm{m}^{2}-\mathrm{day}\right]$, therefore, it becomes

$P_{C+0 \% M t}=P_{0} *\left(\frac{1-X_{C}}{1+\frac{1}{2} X_{C}}\right)$

This gives a value of $110 \mathrm{~g}-\mathrm{mil} /\left[\mathrm{m}^{2}-\right.$ day], which is in good agreement with the measured value of $111 \mathrm{~g}-\mathrm{mil} /\left[\mathrm{m}^{2}-\right.$ day].

As discussed previously, the model of Bharadwaj (equation (6)) fitted well with the experimental data from the annealed PLA nanocomposites (see Figure 13). 
Therefore the permeability of the annealed PLA nanocomposites containing 0 to $5 \mathrm{wt} \%$ montmorillonite can be expressed as follows:

$$
P_{C+n \% M t}=P_{C+0 \% M t} *\left(\frac{1-\emptyset_{F}}{1+\frac{L \emptyset_{F}}{2 D}\left(\frac{2}{3}\right)\left(S+\frac{1}{2}\right)}\right)
$$

By inserting equation (8) into equation (9), the theoretical permeability of semi-crystalline polymer nanocomposites becomes

$$
P_{C+n \% M t}=P_{0} *\left(\frac{1-X_{C}}{1+\frac{1}{2} X_{C}}\right) *\left(\frac{1-\emptyset_{F}}{1+\frac{L \emptyset_{F}}{2 D}\left(\frac{2}{3}\right)\left(S+\frac{1}{2}\right)}\right)
$$

Permeability predicted from equation (10) was plotted together with the experimental data from the semi-crystalline PLA nanocomposites, as shown in Figure 14. When S $=0.15$, the experimental data gives a reasonable fit to the predicted line with $\mathrm{R}^{2}=0.8$. This confirms that the new model fits the experimental data well as the model of Bharadwaj, showing that the new tortuous path model gives a good prediction of the combined effect of crystallinity and nanoclay on water vapour permeability of polymer films.

\section{Conclusions}

PLA nanocomposites containing 0 to $5 \mathrm{wt}$ \% montmorillonite were prepared by melt compounding followed by compression moulding with two different thermal treatments (i.e. quenching and annealing). Both amorphous and semi-crystalline PLA nanocomposite samples were obtained. Thermal properties of the samples were measured by DSC. The crystallinity of the annealed PLA and PLA nanocomposites was found to be $30 \%$. The morphology of crystallites was observed by polarised optical microscopy. The montmorillonite structure was measured using TEM and WAXD. It was confirmed that the nanocomposite structures were intercalated and the 
montmorillonite aspect ratio was about 40 in both quenched and annealed samples. The montmorillonite layers were aligned in the same direction in the quenched samples. However, there was random orientation in the annealed samples due to the crystallisation process.

Water vapour transmission rates through the film samples were measured at $38^{\circ} \mathrm{C}$ and at a relative humidity of $90 \%$. It was found that the measured values of WVTR of the quenched PLA nanocomposites decreased consistently with montmorillonite concentration and the data showed a good fit with the Nielsen model. The measured WVTR data of the annealed PLA nanocomposites fitted the model of Bharadwaj when the montmorillonite orientation was assumed to be nearly random.

A new tortuous model was built based on the models of Nielsen and Bharadwaj to predict the combined effects of crystallinity and nano-filler on the water vapour transmission rates through the polymer films. The new model showed a good fit with the experimental data from the annealed PLA nanocomposites.

\section{Acknowledgements}

The authors would like to acknowledge technical assistance from Dr Zhaoxia Zhou and $\mathrm{Mr}$ Keith Yendall, Department of Materials, Loughborough University, for transmission electron microscopy (TEM) and wide-angle X-ray diffraction (WAXD) respectively.

The authors are also grateful for funding for this work from the Department of Materials, Loughborough University, UK.

\section{References}

Araújo, A., Botelho, G., Oliveira, M., Machado, A. V., 2014. Influence of clay organic 
modifier on the thermal-stability of PLA based nanocomposites. Appl. Clay Sci. 88-89, 144-150. doi:10.1016/j.clay.2013.12.005

Auras, R., Harte, B., Selke, S., 2004. An overview of polylactides as packaging materials. Macromol. Biosci. 4, 835-864. doi:10.1002/mabi.200400043

Bharadwaj, R.K., 2001. Modeling the Barrier Properties of Polymer-layered Silicate Nanocomposites. Macromolecules 34, 9189-9192.

Cocca, M., Lorenzo, M.L. Di, Malinconico, M., Frezza, V., 2011. Influence of crystal polymorphism on mechanical and barrier properties of poly(l-lactic acid). Eur. Polym. J. 47, 1073-1080. doi:10.1016/j.eurpolymj.2011.02.009

Drieskens, M., Peeters, R., Mullens, J., Franco, D., Lemstra, P.J., Hristova-Bogaerds, D.G., 2009. Structure versus properties relationship of poly(lactic acid). I. Effect of crystallinity on barrier properties. J. Polym. Sci. Part B Polym. Phys. 47, 22472258. doi:10.1002/polb

Duan, Z., Thomas, N.L., 2014. Water vapour permeability of poly(lactic acid): Crystallinity and the tortuous path model. J. Appl. Phys. 115, 064903(1-9). doi:10.1063/1.4865168

Duan, Z., Thomas, N.L., Huang, W., 2013. Water vapour permeability of poly(lactic acid) nanocomposites. J. Memb. Sci. 445, 112-118. doi:10.1016/j.memsci.2013.06.008

Espino-Pérez, E., Bras, J., Ducruet, V., Guinault, A., Dufresne, A., Domenek, S., 2013. Influence of chemical surface modification of cellulose nanowhiskers on thermal, mechanical, and barrier properties of poly(lactide) based bionanocomposites. Eur. Polym. J. 49, 3144-3154. doi:10.1016/j.eurpolymj.2013.07.017 
Fukushima, K., Abbate, C., Tabuani, D., Gennari, M., Camino, G., 2009.

Biodegradation of poly(lactic acid) and its nanocomposites. Polym. Degrad. Stab. 94, 1646-1655. doi:10.1016/j.polymdegradstab.2009.07.001

Garlotta, D., 2002. A Literature Review of Poly ( Lactic Acid ). J. Polym. Environ. 9, 63-84.

Gorrasi, G., Tammaro, L., Vittoria, V., Paul, M., Alexandre, M., Dubois, P., 2004. Transport Properties of Water Vapor in Polylactide/Montmorillonite Nanocomposites. J. Macromol. Sci. Part B 43, 565-575. doi:10.1081/MB-120030006

Johansson, C., Clegg, F., 2015. Effect of clay type on dispersion and barrier properties of hydrophobically modified poly(vinyl alcohol)-bentonite nanocomposites. J. Appl. Polym. Sci. 132, 1-25. doi:10.1002/app.42229

Lawrence E. Nielsen, 1967. Models for the Permeability of Filled Polymer Systems. J. Macromol. Sci. Part A - Chem. 1, 929-942.

LeBaron, P.C., Wang, Z., Pinnavaia, T.J., 1999. Polymer-layered silicate nanocomposites: An overview. Appl. Clay Sci. 15, 11-29. doi:10.1016/S0169-1317(99)00017-4

Lim, L.T., Auras, R., Rubino, M., 2008. Processing technologies for poly(lactic acid). Prog. Polym. Sci. 33, 820-852. doi:10.1016/j.progpolymsci.2008.05.004

Ling, X., Spruiell, J.E., 2006. Analysis of the Complex Thermal Behavior of Poly ( L -lactic acid ) Film . I . Samples Crystallized from the Glassy State. J. Polym. Sci. Part B Polym. Phys. 44, 3200-3214. doi:10.1002/polb

Madhavan Nampoothiri, K., Nair, N.R., John, R.P., 2010. An overview of the recent developments in polylactide (PLA) research. Bioresour. Technol. 101, 8493- 
8501. doi:10.1016/j.biortech.2010.05.092

McLauchlin, A.R., Thomas, N.L., 2012. Biodegradable nanocomposites, in: F. Gao (Ed.), Advances in Polymer NanocompositesWoodhead Publishing. Cambridge, pp. $398-430$.

Michaels, A.S., Vieth, W.R., Barrie, J. a., 1963. Diffusion of gases in polyethylene terephthalate. J. Appl. Phys. 34, 13-20. doi:10.1063/1.1729054

Neppalli, R., Causin, V., Marega, C., Modesti, M., Adhikari, R., Scholtyssek, S., Ray, S.S., Marigo, A., 2014. The effect of different clays on the structure, morphology and degradation behavior of poly(lactic acid). Appl. Clay Sci. 87, 278-284. doi:10.1016/j.clay.2013.11.029

Pan, P., Kai, W., Zhu, B., Dong, T., Inoue, Y., 2007. Polymorphous Crystallization and Multiple Melting Behavior of Poly ( $\mathrm{L}$-lactide ): Molecular Weight Dependence. Macromolecules 40, 6898-6905.

Pan, P., Zhu, B., Kai, W., Dong, T., Inoue, Y., 2008. Polymorphic Transition in Disordered Poly ( L -lactide ) Crystals Induced by Annealing at Elevated Temperatures. Macromolecules 41, 4296-4304.

Picard, E., Espuche, E., Fulchiron, R., 2011. Effect of an organo-modified montmorillonite on PLA crystallization and gas barrier properties. Appl. Clay Sci. 53, 58-65. doi:10.1016/j.clay.2011.04.023

Pluta, M., 2006. Melt Compounding of Polylactide / Organoclay : Structure and Properties of Nanocomposites. Physics (College. Park. Md). 44, 3392-3405. doi:10.1002/polb

Rhim, J.-W., Hong, S.-I., Ha, C.-S., 2009. Tensile, water vapor barrier and antimicrobial properties of PLA/nanoclay composite films. Food Sci. Technol. 42, 
612-617. doi:10.1016/j.Iwt.2008.02.015

Sanchez-Garcia, M.D., Gimenez, E., Lagaron, J.M., 2008. Morphology and barrier properties of solvent cast composites of thermoplastic biopolymers and purified cellulose fibers. Carbohydr. Polym. 71, 235-244.

doi:10.1016/j.carbpol.2007.05.041

Sawai, D., Takahashi, K., Imamura, T., Nakamura, K., Kanamoto, T., Hyon, S.-H., 2002. Preparation of Oriented $\beta$-Form Poly ( $L$-lactic acid ) by Solid-State Extrusion. J. Polym. Sci. Part B Polym. Phys. 40, 95-104. doi:10.1002/polb.0000

Tan, B., Thomas, N.L., 2016. A review of the water barrier properties of polymer/clay and polymer/graphene nanocomposites. J. Memb. Sci. 514, 595-612. doi:10.1016/j.memsci.2016.05.026

Tenn, N., Follain, N., Soulestin, J., Crétois, R., Bourbigot, S., Marais, S., 2013. Effect of Nanoclay Hydration on Barrier Properties of PLA / Montmorillonite Based Nanocomposites. J. Phys. Chem. C 117, 12117-12135.

Thellen, C., Orroth, C., Froio, D., Ziegler, D., Lucciarini, J., Farrell, R., D’Souza, N.A., Ratto, J.A., 2005. Influence of montmorillonite layered silicate on plasticized poly(I-lactide) blown films. Polymer (Guildf). 46, 11716-11727. doi:10.1016/j.polymer.2005.09.057

Yano, K., Usuki, A., Okada, A., 1997. Synthesis and Properties of Polyimide-Clay Hybrid Films. J. Polym. Sci. Part A Polym. Chem. 35, 2289-2294.

Yano, K., Usuki, A., Okada, A., Kurauchi, T., Kamigaito, O., 1993. Synthesis and Properties of Polyimide-Clay Hybrid. J. Polym. Sci. Part A Polym. Chem. since 31, 2493-2498.

Yasuniwa, M., Tsubakihara, S., Sugimoto, Y., Nakafuku, C., 2004. Thermal Analysis 
of the Double-Melting Behavior of Poly ( L-lactic acid ). J. Polym. Sci. Part B Polym. Phys. 42, 25-32.

Zenkiewicz, M., Richert, J., 2008. Permeability of polylactide nanocomposite films for water vapour, oxygen and carbon dioxide. Polym. Test. 27, 835-840. doi:10.1016/j.polymertesting.2008.06.005

Zenkiewicz, M., Richert, J., Róański, A., 2010. Effect of blow moulding ratio on barrier properties of polylactide nanocomposite films. Polym. Test. 29, 251-257. doi:10.1016/j.polymertesting.2009.11.008 


\section{Graphical Abstract}

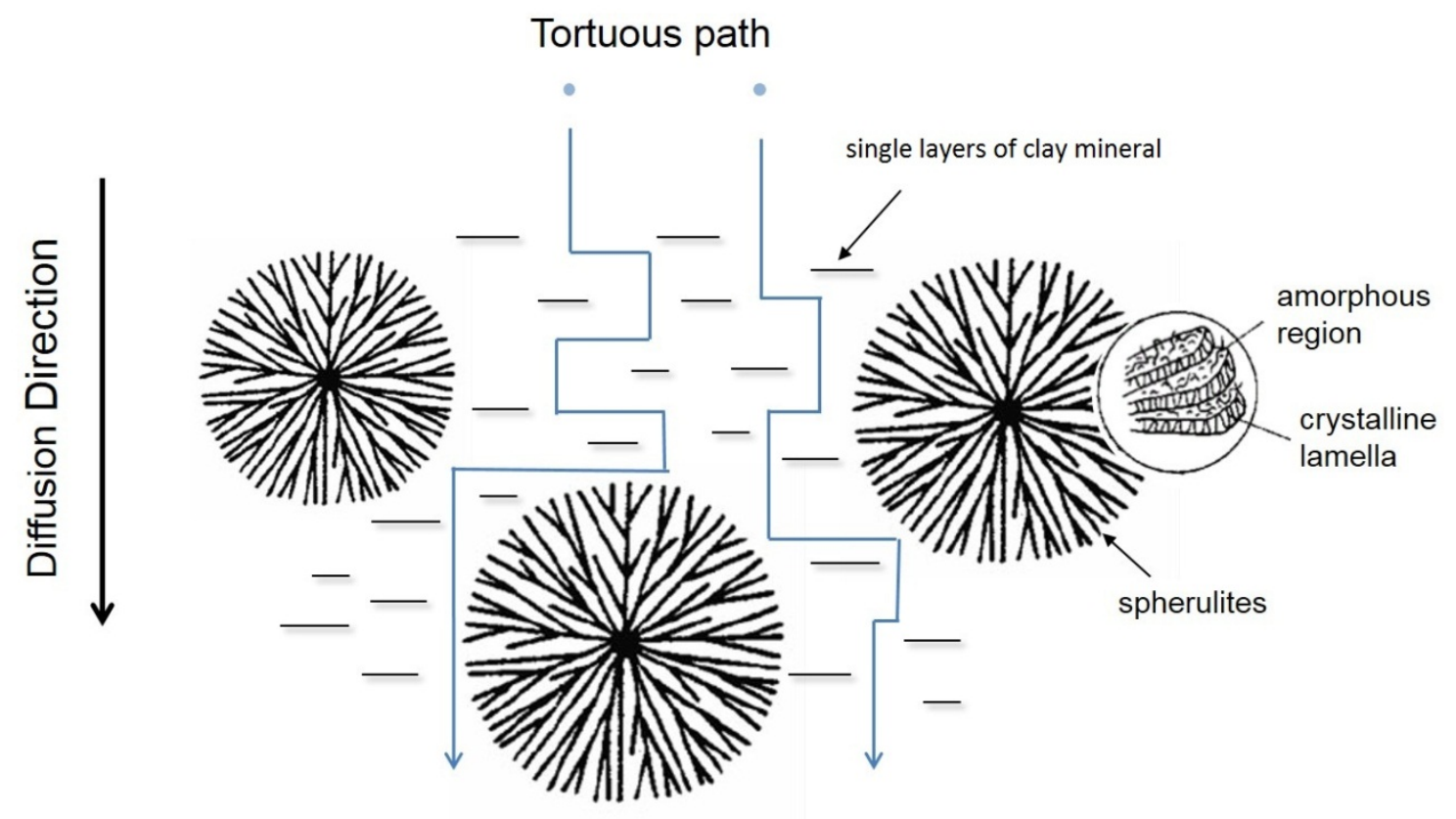

\section{Highlights}

- A new tortuous path model predicts the permeability of polymer nanocomposite films

- Polymer crystallinity, montmorillonite content, aspect ratio and orientation are included

- The model fits well with experimental data from annealed polymer nanocomposites 
Table 1 DSC data for all samples

\begin{tabular}{|c|c|c|c|}
\hline & $\mathrm{Tg}$ & $\mathrm{Tm}$ & $\mathrm{Xc}$ \\
\hline Quenched PLA & $56 \pm 1{ }^{\circ} \mathrm{C}$ & ---- & $0 \%$ \\
\hline Quenched PLA+1wt.\% montmorillonite & $55 \pm 1{ }^{\circ} \mathrm{C}$ & ---- & $0 \%$ \\
\hline Quenched PLA+2wt.\% montmorillonite & $52 \pm 1{ }^{\circ} \mathrm{C}$ & ---- & $0 \%$ \\
\hline Quenched PLA+3wt.\% montmorillonite & $53 \pm 1{ }^{\circ} \mathrm{C}$ & ---- & $0 \%$ \\
\hline Quenched PLA+4wt.\% montmorillonite & $51 \pm 1{ }^{\circ} \mathrm{C}$ & ---- & $0 \%$ \\
\hline Quenched PLA+5wt.\% montmorillonite & $52 \pm 1{ }^{\circ} \mathrm{C}$ & ---- & $0 \%$ \\
\hline Annealed PLA & $57 \pm 1{ }^{\circ} \mathrm{C}$ & $170 \pm 1{ }^{\circ} \mathrm{C}$ & $30 \pm 1 \%$ \\
\hline Annealed PLA+1wt.\% montmorillonite & $56 \pm 1{ }^{\circ} \mathrm{C}$ & $170 \pm 1{ }^{\circ} \mathrm{C}$ & $32 \pm 1 \%$ \\
\hline Annealed PLA+2wt.\% montmorillonite & $56 \pm 1{ }^{\circ} \mathrm{C}$ & $169 \pm 1{ }^{\circ} \mathrm{C}$ & $31 \pm 1 \%$ \\
\hline Annealed PLA+3wt.\% montmorillonite & $57 \pm 1{ }^{\circ} \mathrm{C}$ & $169 \pm 1{ }^{\circ} \mathrm{C}$ & $32 \pm 1 \%$ \\
\hline Annealed PLA+4wt.\% montmorillonite & $56 \pm 1{ }^{\circ} \mathrm{C}$ & $170 \pm 1{ }^{\circ} \mathrm{C}$ & $31 \pm 1 \%$ \\
\hline Annealed PLA+5wt.\% montmorillonite & $56 \pm 1{ }^{\circ} \mathrm{C}$ & $170 \pm 1{ }^{\circ} \mathrm{C}$ & $30 \pm 1 \%$ \\
\hline
\end{tabular}


Table 2 Summary of results of water vapour transmission rate

\begin{tabular}{|c|c|c|}
\hline & Crystallinity & WVTR (gm-mil/[m²-day]) \\
\hline Quenched PLA & $0 \%$ & $180 \pm 3$ \\
\hline Quenched PLA+1wt.\% montmorillonite & $0 \%$ & $165 \pm 3$ \\
\hline Quenched PLA+2wt.\% montmorillonite & $0 \%$ & $147 \pm 2$ \\
\hline Quenched PLA+3wt.\% montmorillonite & $0 \%$ & $134 \pm 3$ \\
\hline Quenched PLA+4wt.\% montmorillonite & $0 \%$ & $118 \pm 1$ \\
\hline Quenched PLA+5wt.\% montmorillonite & $0 \%$ & $112 \pm 3$ \\
\hline Annealed PLA & $30 \pm 1 \%$ & $111 \pm 2$ \\
\hline Annealed PLA+1wt.\% montmorillonite & $32 \pm 1 \%$ & $107 \pm 3$ \\
\hline Annealed PLA+2wt.\% montmorillonite & $31 \pm 1 \%$ & $87 \pm 2$ \\
\hline Annealed PLA+3wt.\% montmorillonite & $32 \pm 1 \%$ & $86 \pm 2$ \\
\hline Annealed PLA+4wt.\% montmorillonite & $31 \pm 1 \%$ & $88 \pm 1$ \\
\hline Annealed PLA+5wt.\% montmorillonite & $30 \pm 1 \%$ & \\
\hline
\end{tabular}




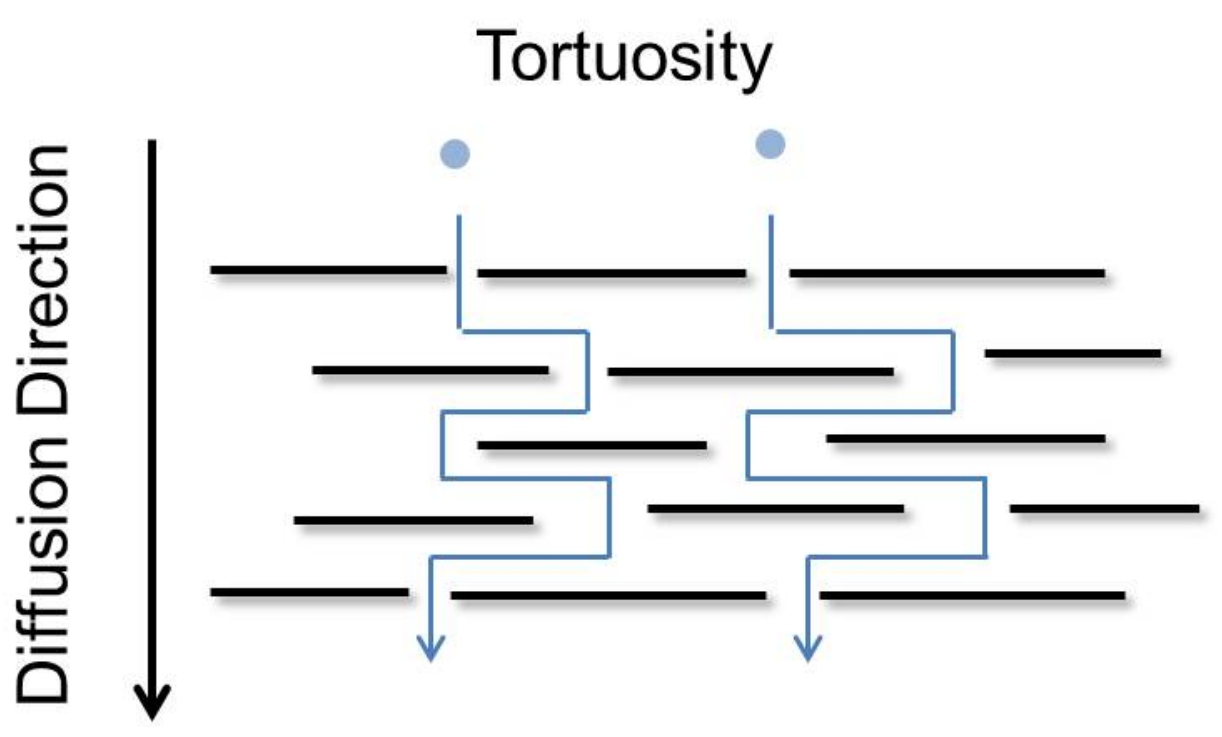

Figure 1 Schematic diagram of the tortuous path model

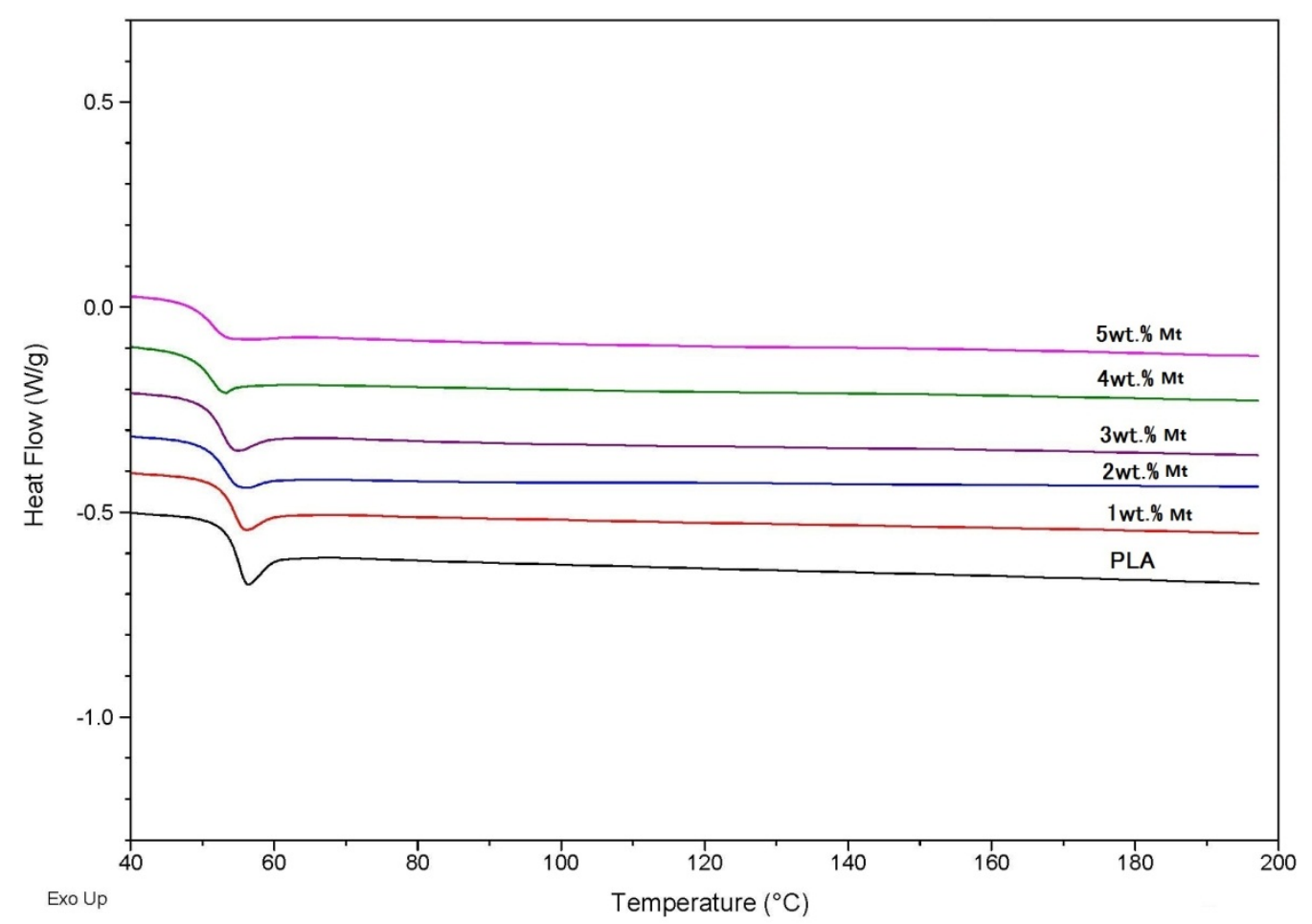

Figure 2. DSC heating scan for the amorphous PLA and PLA nanocomposites 


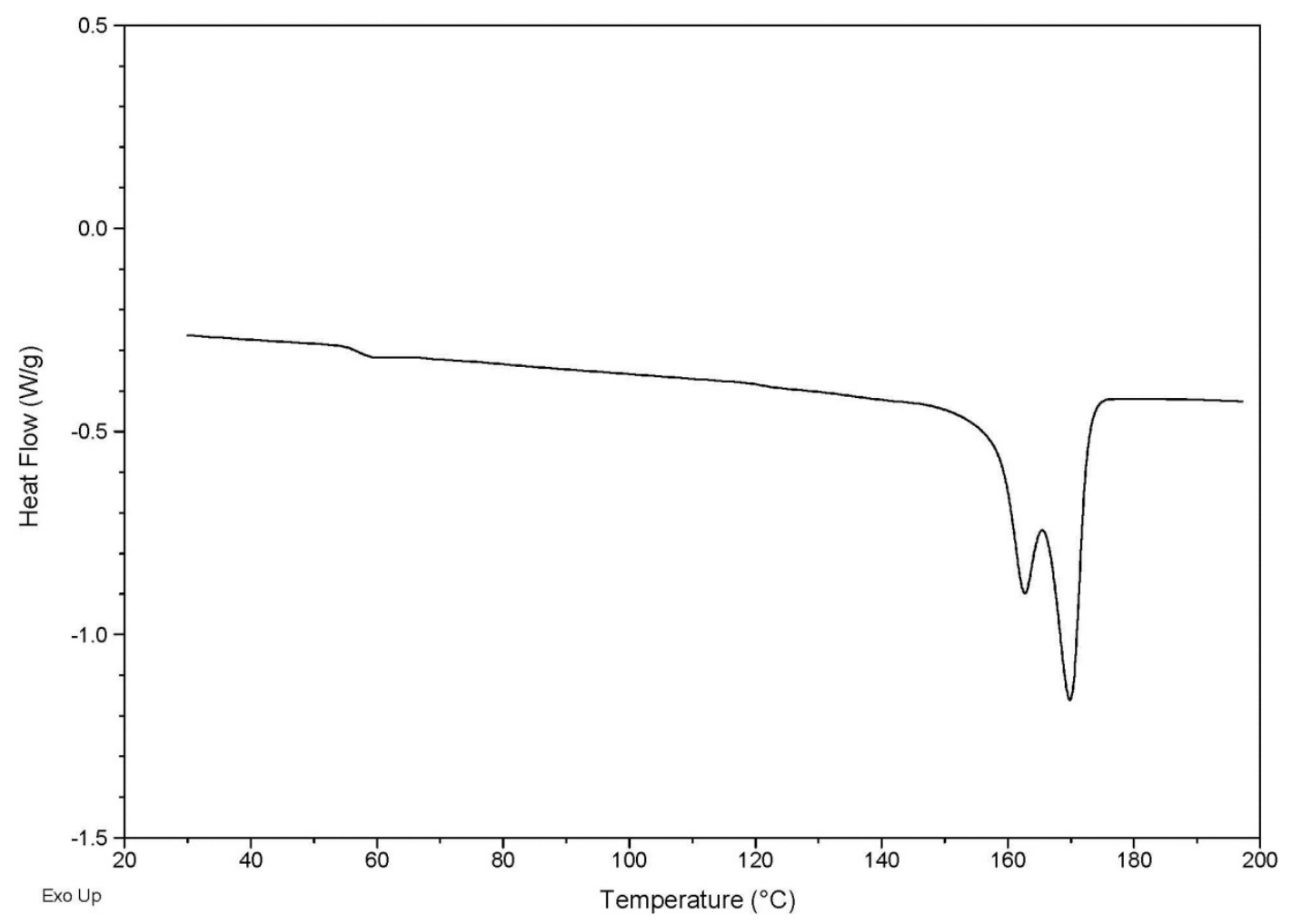

Figure 3. DSC heating scan for the annealed PLA

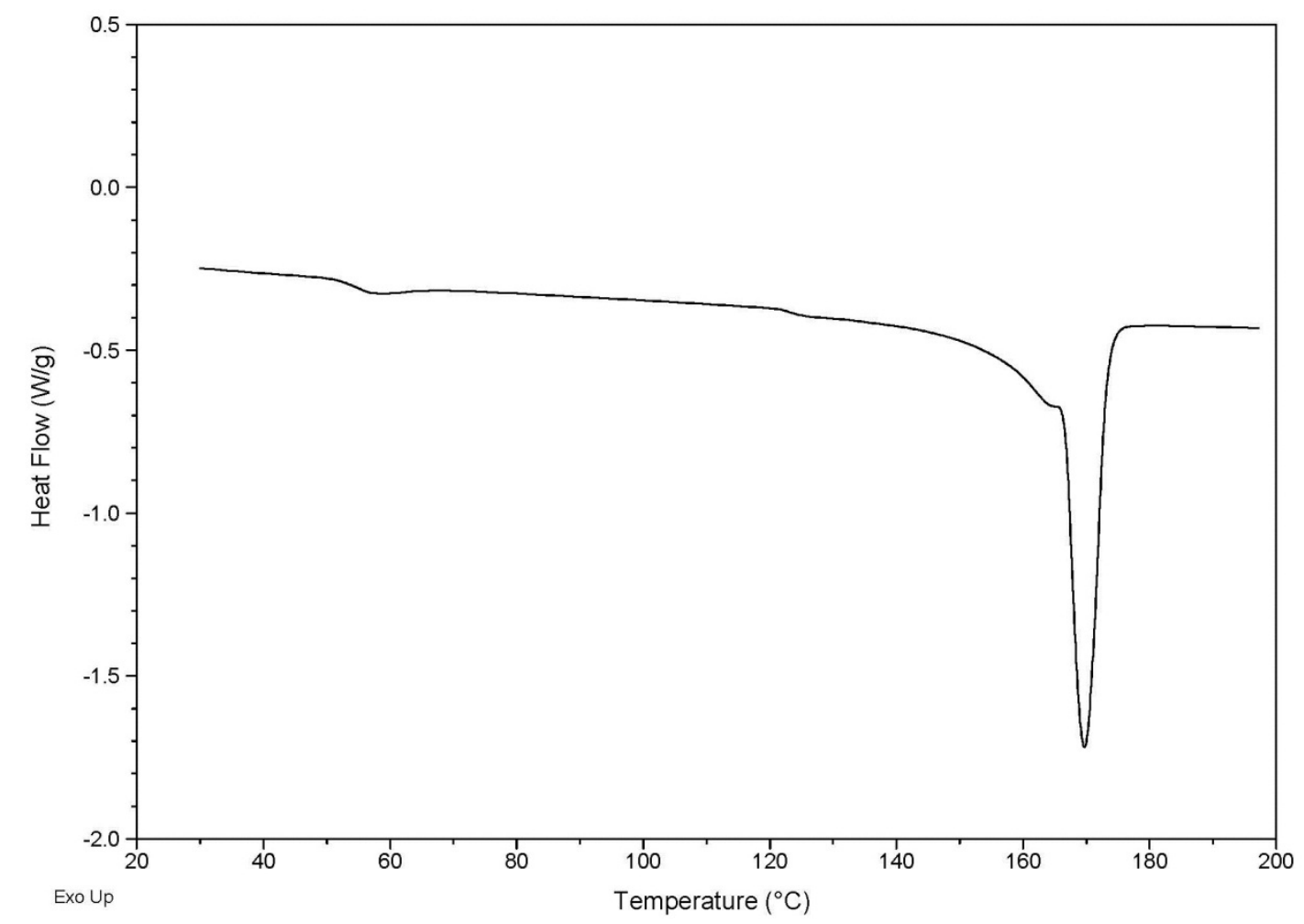

Figure 4. DSC heating scan for the annealed PLA nanocomposite with $5 \mathrm{wt} . \%$ montmorillonite 

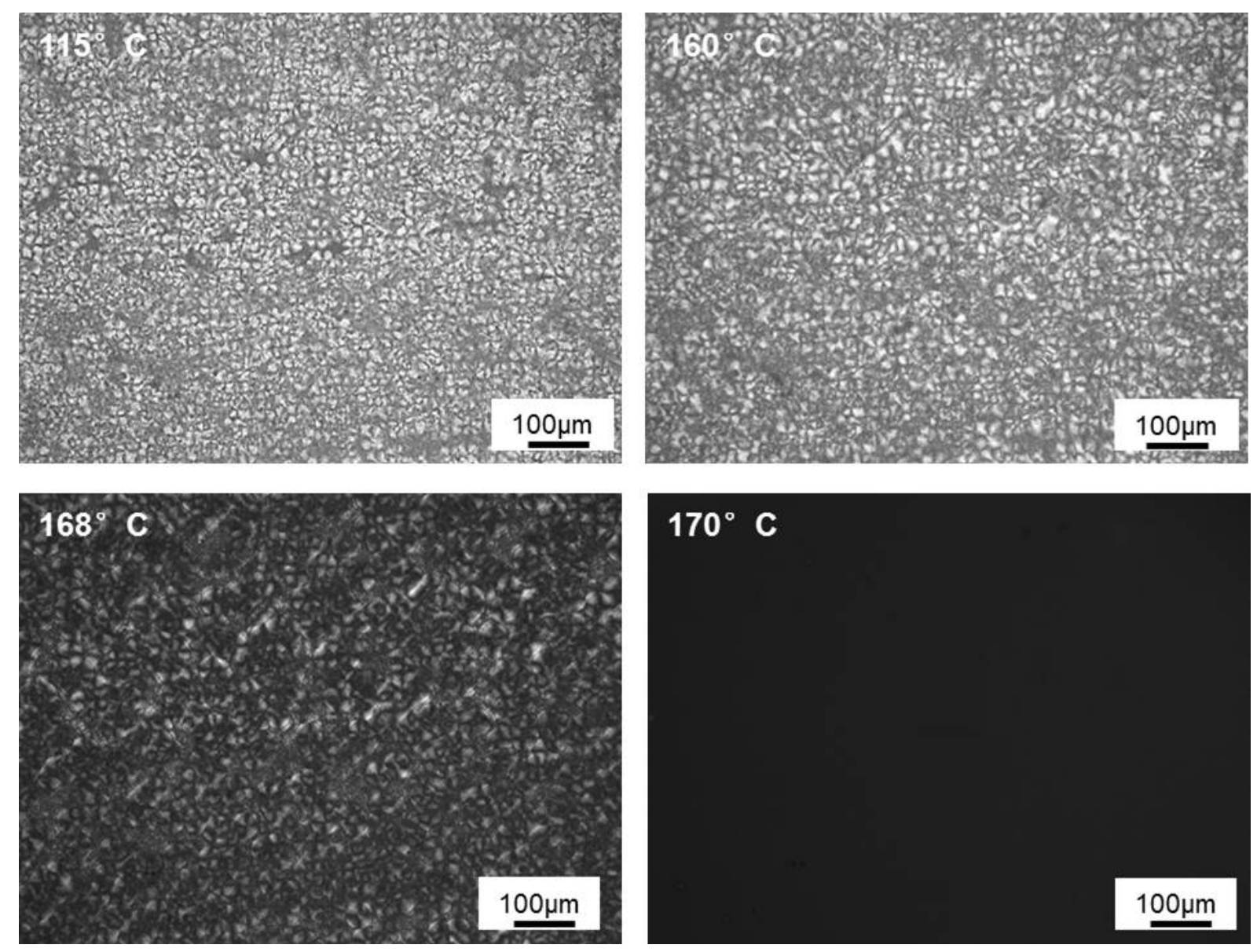

Figure 5. Annealed PLA viewed in hot stage polarised optical microscope when heated at $115^{\circ} \mathrm{C}, 160^{\circ} \mathrm{C}, 168^{\circ} \mathrm{C}$ and $170^{\circ} \mathrm{C}$ 


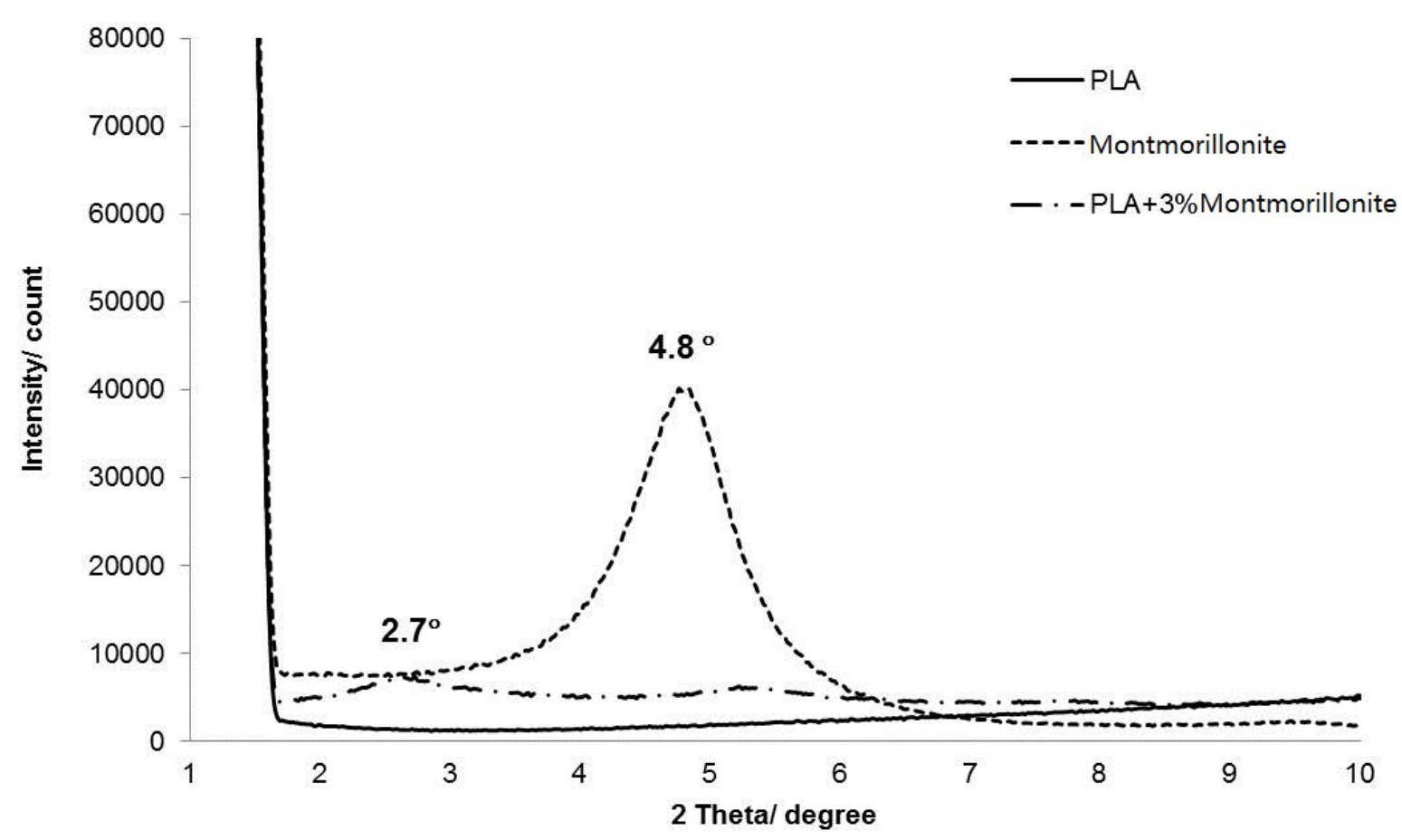

Figure 6. WAXD traces of montmorillonite, PLA and PLA nanocomposite

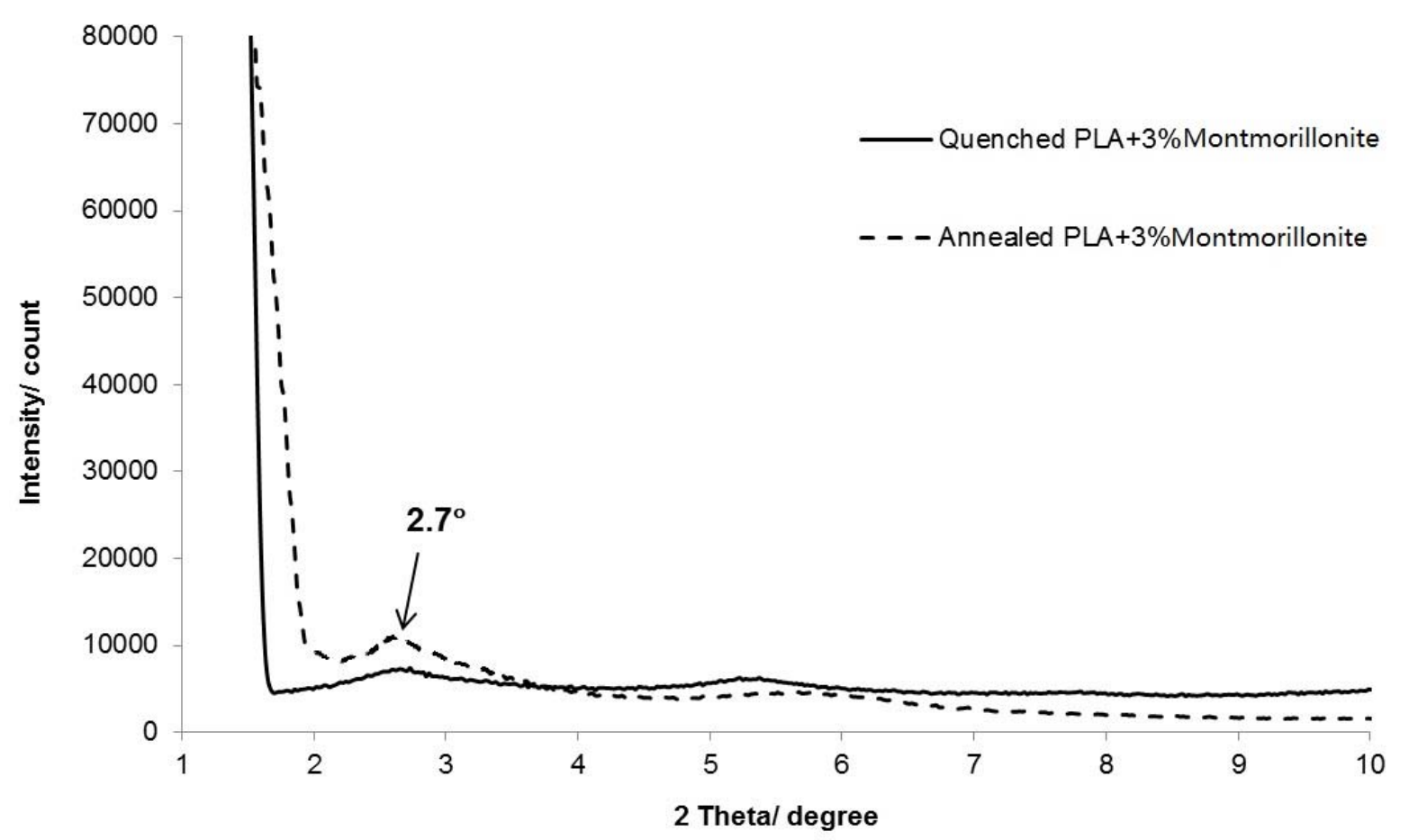

Figure 7. WAXD traces of quenched and annealed PLA nanocomposites with $3 \mathrm{wt} . \%$ montmorillonite 

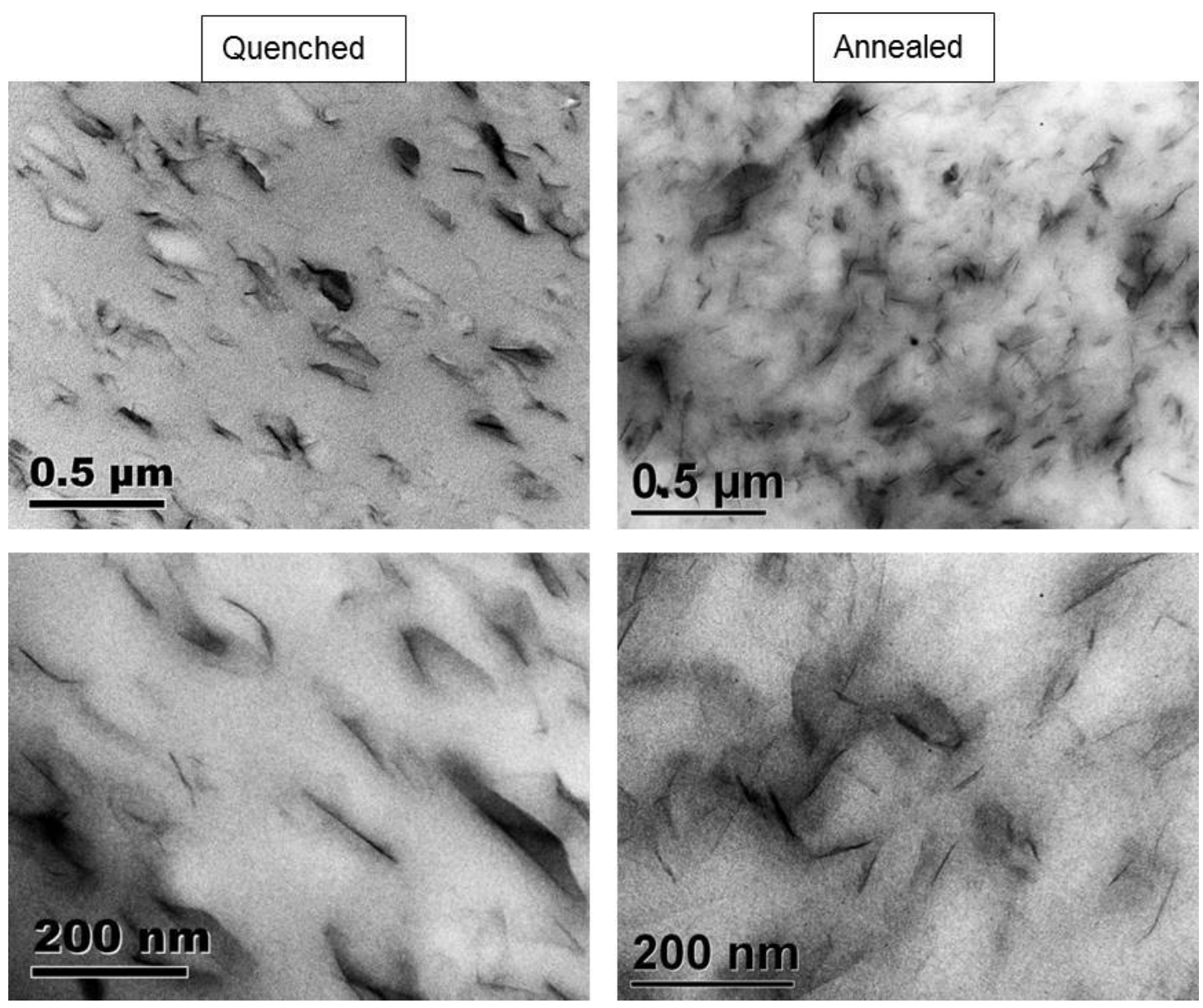

Figure 8 TEM images of quenched and annealed PLA nanocomposites containing 1 wt. \% montmorillonite at magnifications of $60 \mathrm{k}$ and $200 \mathrm{k}$ 


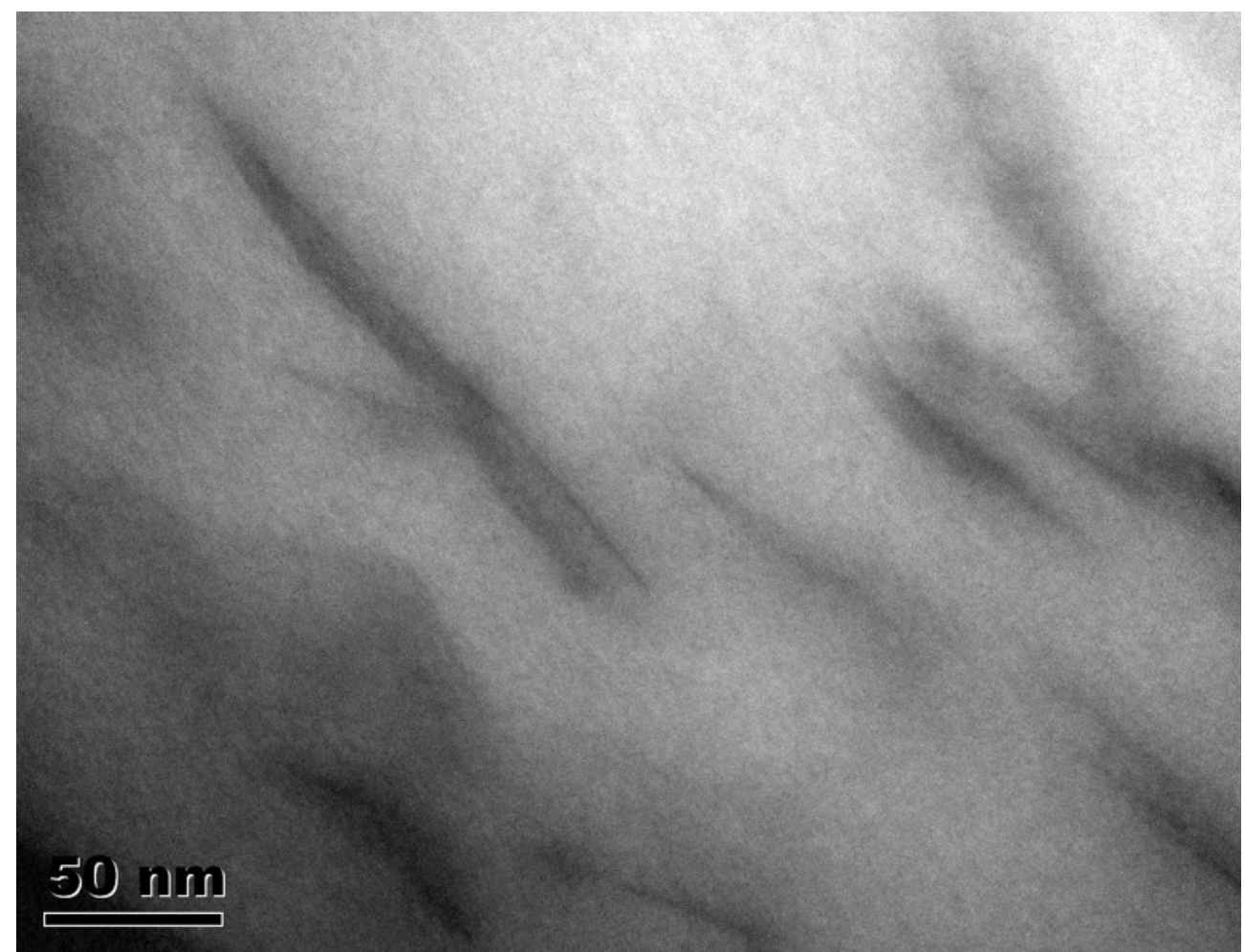

Figure 9 Transmission electron micrograph of quenched PLA nanocomposite with 1 wt. $\%$ montmorillonite at $400 \mathrm{~K}$ magnification

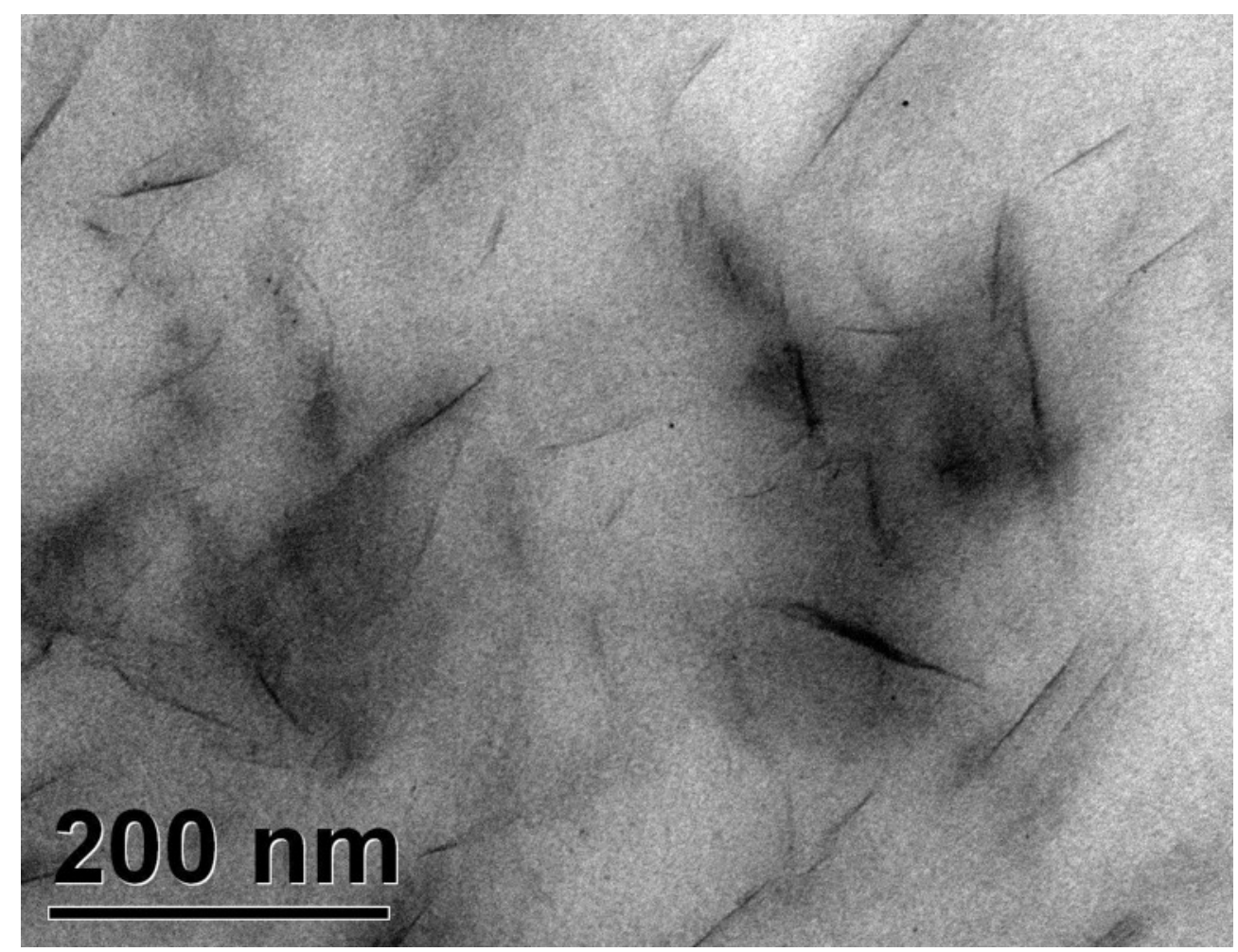

Figure 10 TEM images of annealed PLA nanocomposite with $1 \mathrm{wt} . \%$ montmorillonite at $200 \mathrm{k}$ magnification 


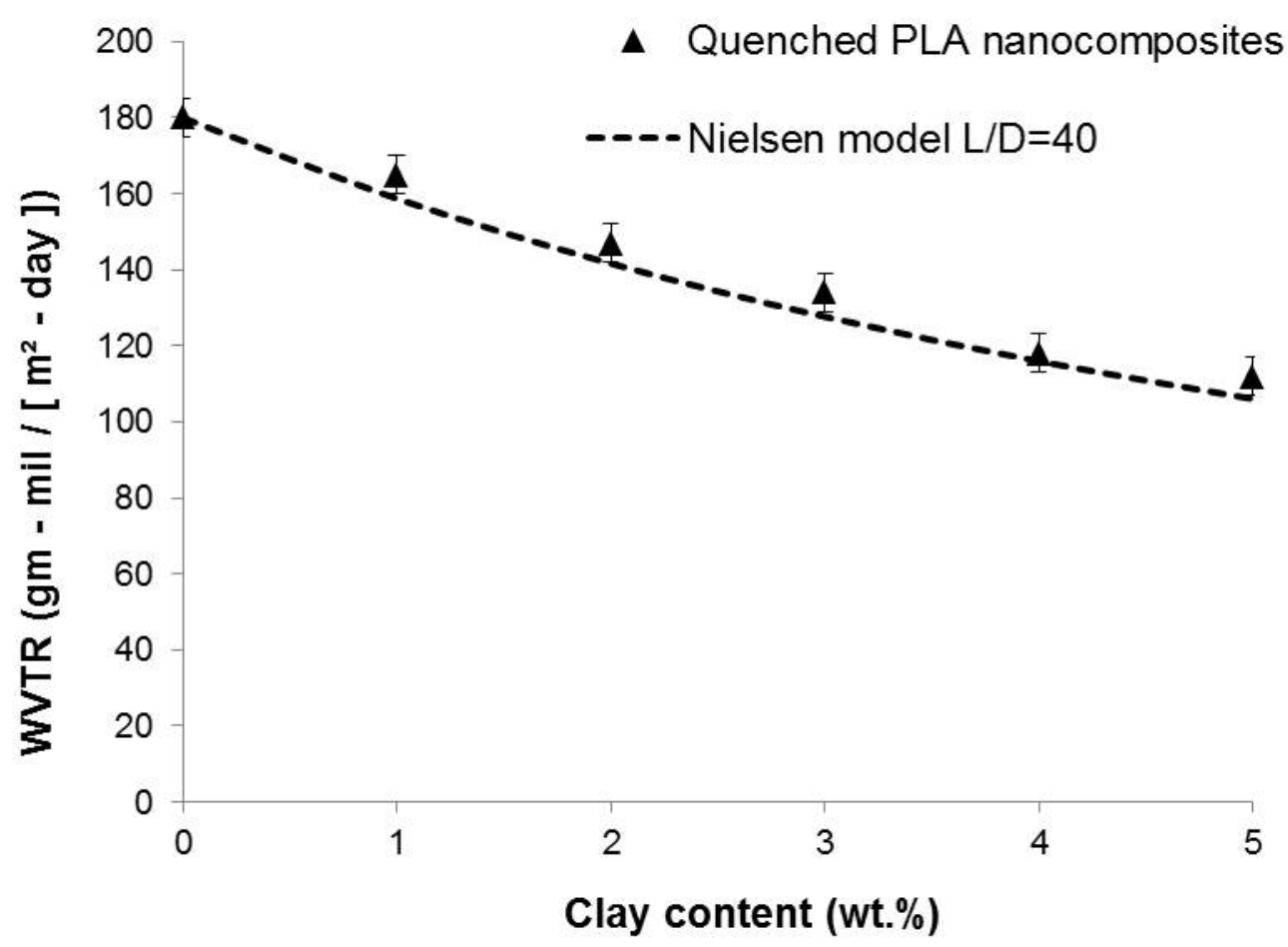

Figure 11 Water vapour permeabilities of quenched PLA and PLA nanocomposites in comparison with Nielsen theoretical values (volume fraction was converted to weight fraction)

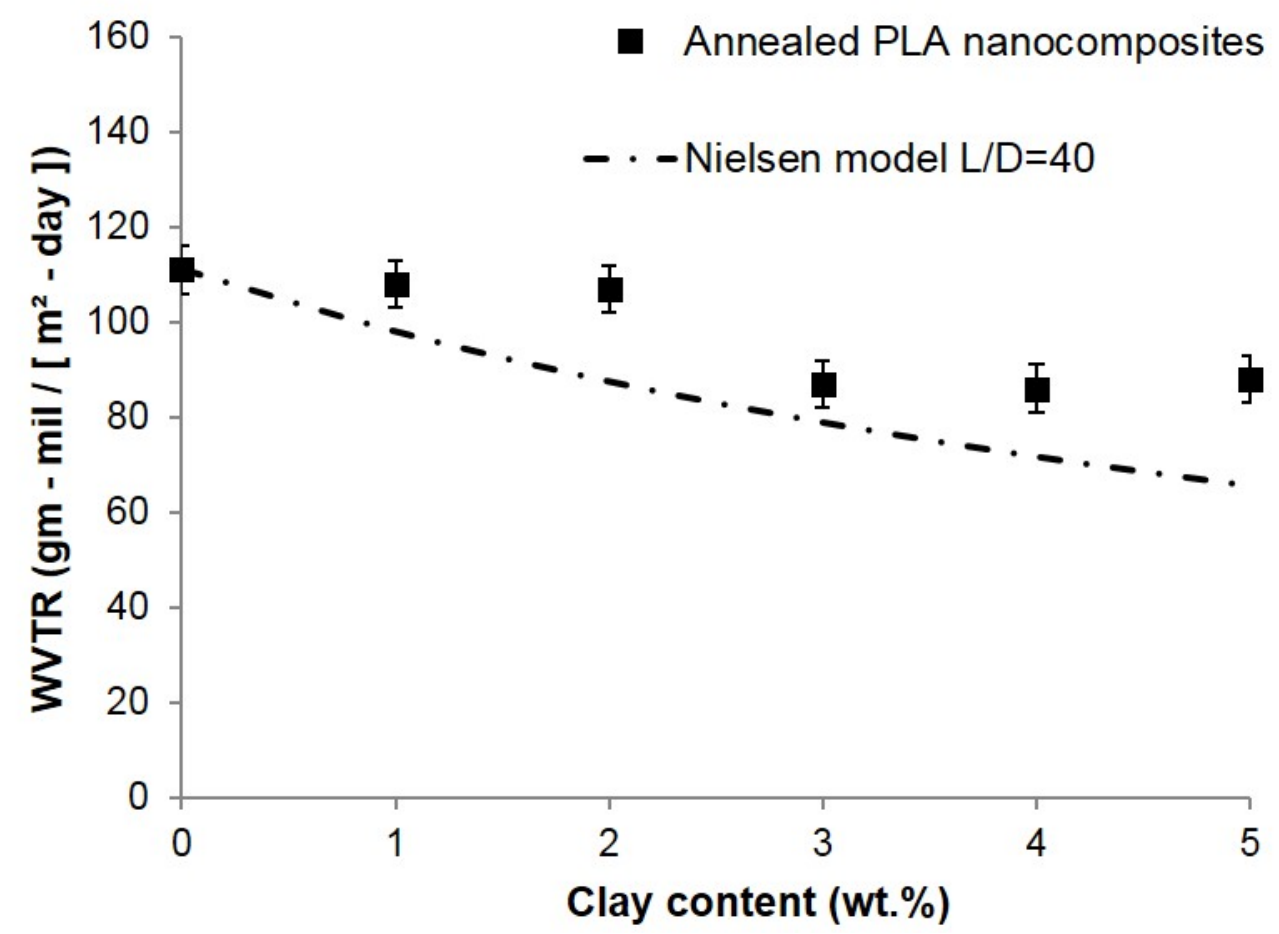

Figure 12. Water vapour permeabilities of annealed PLA and PLA nanocomposites in comparison with Nielsen theoretical values (volume fraction was converted to weight fraction) 


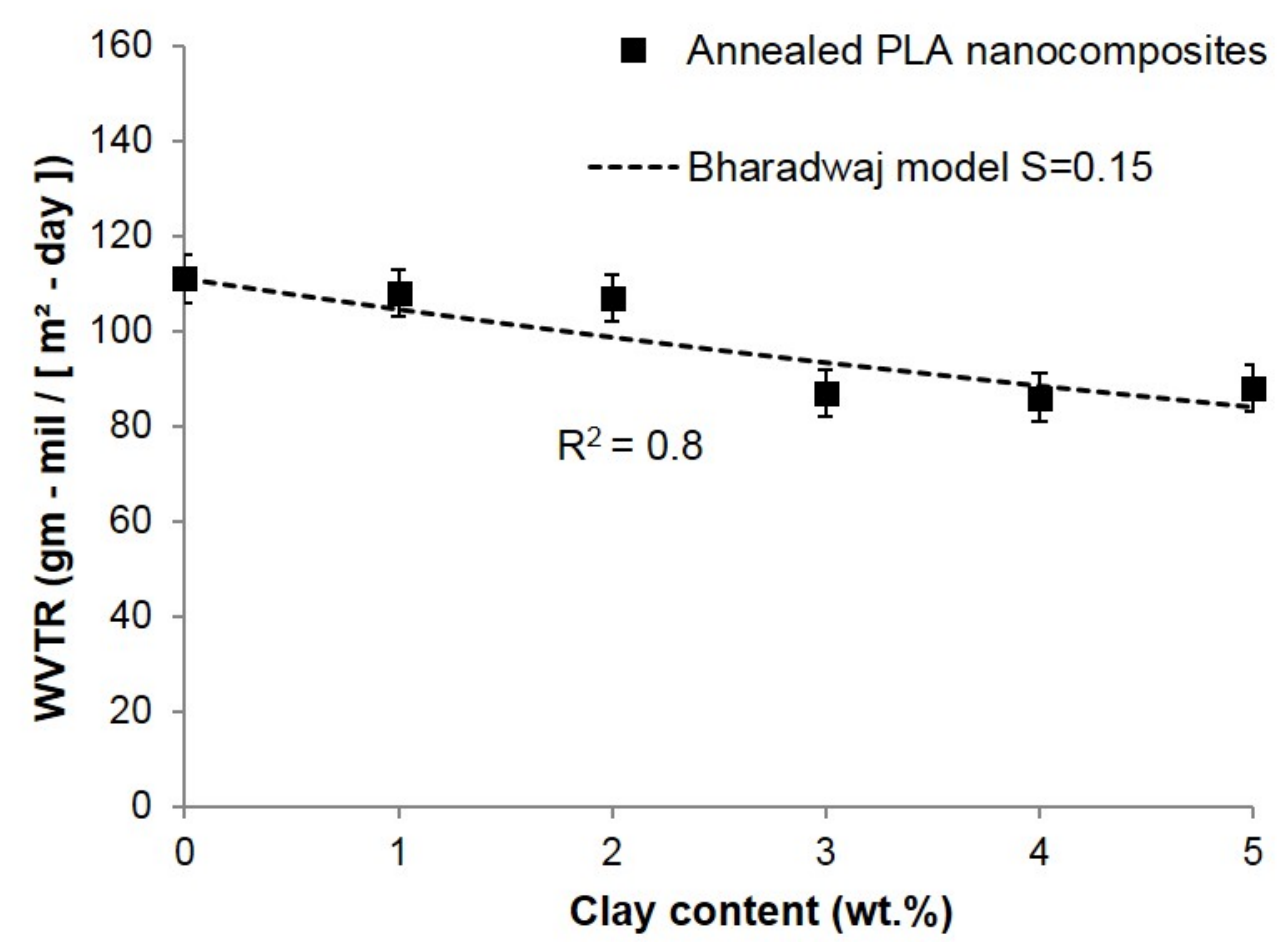

Figure 13 Water vapour permeabilities of annealed PLA and PLA nanocomposites in comparison with theoretical values predicted from the Bharadwaj model

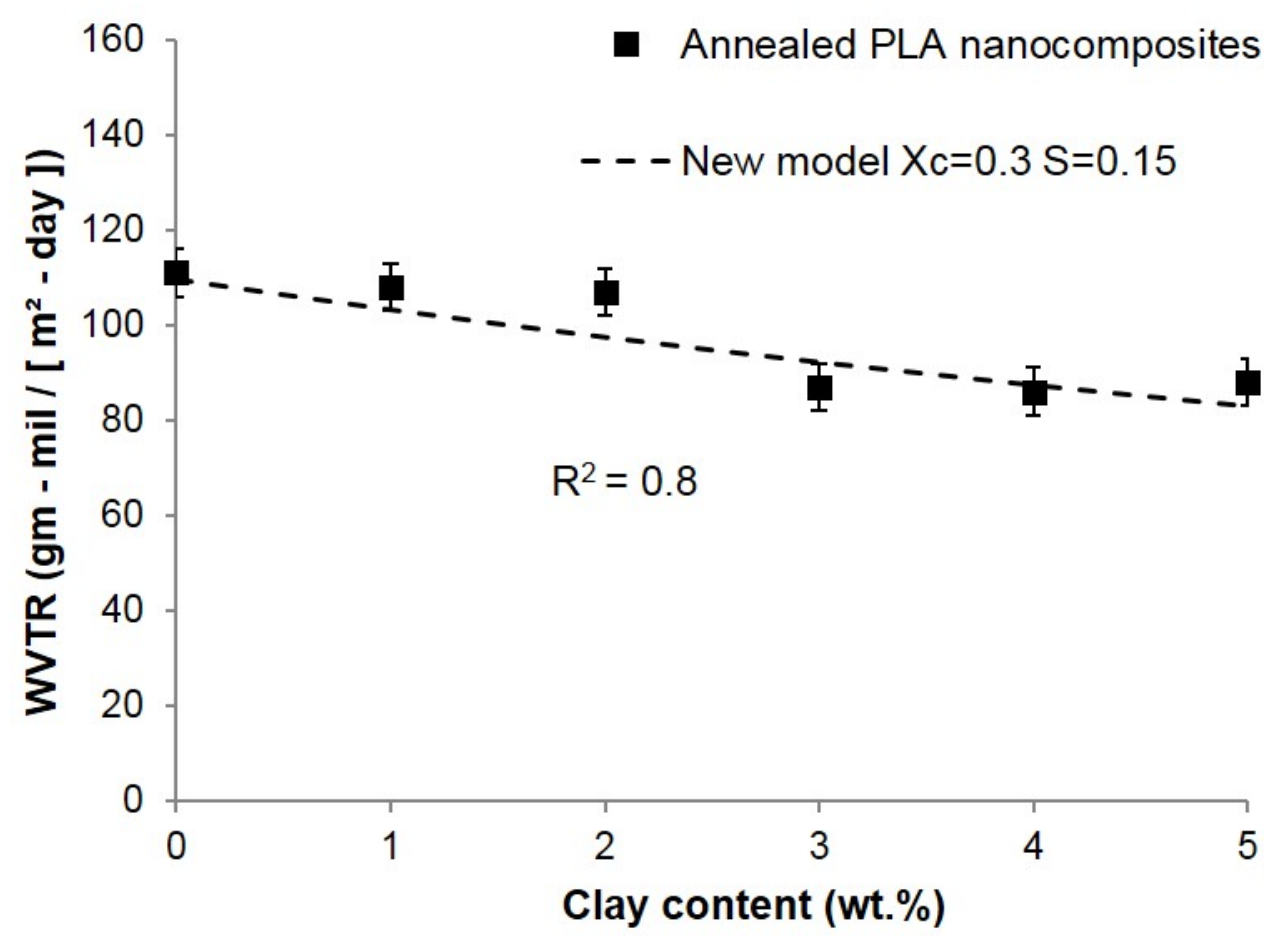

Figure 14. Water vapour permeabilities of annealed PLA nanocomposites in comparison with theoretical values predicted from the new model in equation (10) 